\title{
Chinese Students' English-speaking Anxiety in Asking Questions in the MSc TESOL Classroom
}

\author{
Peng Wang ${ }^{1} \&$ Randhir Roopchund ${ }^{2}$ \\ ${ }^{1}$ Moray House School of Education, University of Edinburgh, Edinburgh, UK \\ ${ }^{2}$ Department of Management, Université des Mascareignes, Mauritius \\ Correspondence: Peng Wang, School of Foreign Languages, Huazhong Agricultural University, No.1 Shizishan \\ Street, Hongshan District, Wuhan, Hubei Province, 430070, P.R.China. E-mail: maxwang360@126.com
}

Received: January 14, 2015 Accepted: January 31, 2015 Online Published: February 28, 2015

doi:10.5430/ijelt.v2n2p1 URL: http://dx.doi.org/10.5430/ijelt.v2n2p1

\begin{abstract}
This study explores the nature of anxiety in asking questions in class from the perspective of seven Chinese learners of English (ESL), with reference to their self-reflective accounts of emotional difficulties encountered in a UK university setting. Through the use of an in-depth semi-structured qualitative interview format, this study identified the effects, sources, and coping strategies pertaining to these learners' anxiety in asking questions in class. This anxiety exerts compound effects on respondents with respect to their mind, body and actual speaking performance. A series of factors contributing to this anxiety are reported by respondents, which can be categorised as 1) personal and interpersonal anxiety; 2) learner beliefs about English language learning; 3) role of instructors; 4) students' personality; 5) students' educational and cultural background; and 6) time for asking questions. Effective strategies for coping with this anxiety reported by respondents mainly consist of 1) preparation; 2) self-encouragement; 3) peer seeking; 4) relaxation; 5) practice; and 6) ignoring others' negative evaluations. Recommendations for EFL/ESL instructors mainly concern 1) instructors' awareness of students' language anxiety 2) instructors' attitudes towards students' questions 3) instructors' feedback to students' questions 4) instructors' classroom management. Recommendations for EFL/ESL learners are almost the same as those strategies respondents reported. This study has enriched the understanding of foreign language anxiety from the perspective of foreign language classroom speaking anxiety in asking questions in class. Future research should check the effectiveness of the coping strategies reported in this study and look into other aspects of foreign language speaking anxiety.
\end{abstract}

Keywords: foreign language speaking anxiety, asking questions in class, Chinese students

\section{Introduction}

\subsection{Background and Context}

In the past two decades, UK universities have seen an evident increase in the application and admission of postgraduate students, among whom Chinese students represent the largest group and the numbers are increasing. Although Chinese postgraduates studying in the UK have reached the language entry requirements, and such a level of English is assumed a sufficient starting point for coping with postgraduate academic demands, various linguistic challenges of studying in a foreign language environment have been uncovered. Comparing native Chinese speakers with native English speakers, Huang (1998) found that the former experienced higher English anxiety levels when trying to combine thinking skills with speaking and listening in lectures and interactive workshops. Further, Kim (2006) reported that the majority of respondents felt that asking questions of the instructor in classes was one of the most anxiety-provoking activities.

In the past two decades, there has been an amount of research into foreign language anxiety (FLA). As an affective factor, anxiety has been found to have a debilitating effect on the language learning process. Much quantitative research has reported that FLA negatively correlates with the language performance (Horwitz, 2001). Yet, no consistent results were obtained (Matsuda \& Gobel, 2004; Young, 1991). Further, it has been demonstrated that FLA is too specific to be assessed by general anxiety measures (MacIntyre \& Gardner, 1989, 1991a).

In educational research, there are mainly three types of anxiety, namely, trait anxiety, state anxiety and situational 
anxiety. Research into FLA has illustrated that FLA should be classed as a situation-specific anxiety (Horwitz, 2001; MacIntyre \& Gardner, 1991b). Based upon this understanding of FLA, Horwitz, Horwitz and Cope (1986) defined FLA as "a distinct complex of self-perceptions, beliefs, feelings and behaviours related to classroom language learning arising from the uniqueness of the language learning process" (p. 128). Moreover, a 33-item foreign language classroom anxiety scale (FLCAS) was created and utilised in a large number of research studies (Horwitz, 2001).

A great deal of research studies on FLA have been conducted from four different language skills, listening, reading, writing and speaking. Foreign language classroom anxiety seems to be most related to speaking than other three skills (Horwitz et al., 1986; Horwitz \& Young, 1991; Liu, 2007). A large amount of research has suggested that speaking in a classroom in front of classmates and teachers is probably the most anxiety-provoking activity (e.g., Aida, 1994; Horwitz et al., 1986; Koch \& Terrell, 1991; Liu \& Jackson, 2008; MacIntyre. 2007; Mak \& White, 1997; Price, 1991; Young, 1990).

As mentioned above, many studies have noted that FLA has a negative effect upon the language performance. Therefore, foreign language classroom speaking anxiety (FLCSA) has also been found to exert an unfavourable effect on the speaking performance and language learning process (Liu, 2007).

Although a great number of studies have investigated the FLCSA in the EFL context, such as China, Turkey, Vietnam, there are much less studies conducted in the ESL context where English is the main language of communication, and is spoken very frequently both in class and out of class. It is possible that students' speaking anxiety in an ESL class seems to be higher than that in an EFL class, because ESL classroom demands that students mentally work on several jobs simultaneously, such as comprehending what the teacher says, retrieving previous knowledge to understand the lecture, forming and asking questions, expressing ideas, and note-taking (Huang, 1998). Furthermore, in the previous studies pertaining to language speaking anxiety in class, respondents mainly consist of undergraduates and secondary school students. Even though some studies also concern postgraduates, there seems no profound exploration on postgraduates' speaking anxiety in class. Although postgraduates studying in the UK are mostly advanced English learners, they still encounter English speaking anxiety in class.

In addition, Woodrow (2006) found that Chinese English learners were more anxious than other ethnic groups because of their Confucian culture. Based on these considerations, therefore, it is necessary and important to look into the speaking anxiety of Chinese postgraduates studying in the ESL context, in order to explore the effects of this speaking anxiety, the factors contributing to their speaking anxiety, and strategies they have used to cope with their speaking anxiety.

Moreover, as a common classroom activity, students' question asking is considered very important and facilitative to enhance their understanding of knowledge as well as to improve their cognitive development. It has been found that students feel anxious about asking questions in class, and they ask questions less frequently than teachers in class (Dillon, 1988). Therefore, it is necessary to investigate this specific classroom activity from the perspective of FLCSA, that is, the phenomenon of students experiencing speaking anxiety in terms of asking questions in class.

\subsection{Problem Statement}

Although Chinese MSc TESOL students studying in the University of Edinburgh are mostly advanced English users, they still felt anxious about speaking English in TESOL classes. To be specific, it was found that they had low motivation and frequency to ask questions publicly in class. Since asking questions is of great importance to students' overall learning and development (Dillon, 1988), it is assumed that students' unwillingness to ask questions in class could impede their effective and efficient learning. There is little information as to why these students experienced this particular anxiety. Hence, an in-depth exploration of this phenomenon is needed in order to discover the contributing factors to this anxiety, and to propose possible strategies for coping with this anxiety. This, in turn, would help the students reduce their anxiety and enhance their motivation of asking questions in class.

\subsection{Purpose Statement and Research Questions}

The purpose of this study is to explore, with 7 Chinese master students, their perceptions of the effects of their anxiety in asking questions, the reasons why they feel anxious about asking questions, and what strategies they have used to effectively cope with this anxiety. To accomplish this purpose, the following research questions are addressed:

RQ1: What do Chinese MSc TESOL students perceive are the effects of their anxiety in asking questions in class? 
RQ2: What do Chinese MSc TESOL students perceive are the factors that contribute to their anxiety in asking questions in class?

RQ3: What strategies do Chinese MSc TESOL students adopt to effectively cope with their anxiety in asking questions in class?

\subsection{Rationale and Significance}

The rationale for this study emanates from the researcher's desire to find out countermeasures to reduce students' foreign language speaking anxiety in class, motivate them to ask questions in class, and thus help them effectively and efficiently engage in the classroom learning. As a 'traveller' in this master programme journey, the researcher has obtained a profound sense of anxiety regarding asking questions in class. In addition, through careful observation of his classmates in class and informal communication with them after class, the researcher found that this anxiety was not only happening upon himself, but also prevalent among other 'travellers' on the same journey. More importantly, this anxiety resulted in many negative consequences such as preventing them from speaking English in class, demotivating them to clarify confusion, and even making some of them give up attending classes. Hence, holding an emic standpoint, the researcher was desirable and passionate to hear other students' stories and voices in order to gain an in-depth and comprehensive understanding of this particular anxiety. As Booth, Colomb, and Williams (2008) state, a research problem is driven by "incomplete knowledge or flawed understanding. You solve it not by changing the world but by understanding it better" (p. 59). Thus, the researcher hoped that a better understanding of this special anxiety would contribute to the theoretical construct of FLA, and more importantly, provide practical implications to help students reduce this anxiety and improve their overall learning.

\subsection{Definitions of Key Terminology}

Foreign Language Anxiety (FLA): a distinct complex of self-perceptions, beliefs, feelings, and behaviours related to classroom language learning arising from the uniqueness of the language learning process (Horwitz, Horwitz, \& Cope, 1986, p. 128).

Foreign Language Classroom Speaking Anxiety (FLCSA): foreign language anxiety induced by speaking a foreign language in a classroom environment.

English as a Foreign Language (EFL) Context: a community where English is not spoken as a first language.

English as a Second Language (ESL) Context: a community where English is spoken as a first language.

Although this study is conducted in an ESL context, FLA is used to refer to language anxiety in both ESL and EFL contexts in order not to generate confusion.

\section{Method}

\subsection{Rationale for Qualitative Approach}

FLA is a subjective experience, which varies from individual to individual. In order to capture the diverse range of students' experiences, a qualitative approach was considered as an appropriate strategy as "it begins with individuals and sets out to understand and interpret their experiences of a particular phenomenon" (Cohen, Manion $\&$ Morrison, 2000, p. 23). A qualitative approach enabled the researcher to hold an emic perspective (Hickerson, 1992) and understand the subjective world of human experience by making an effort to get inside the person and to understand from within (Barbour, 2008; Bogdan \& Biklen, 2007; Denzin \& Lincoln, 2008; Merriam, 2009). Furthermore, previous studies of FLA were predominantly quantitative in nature (Price, 1991), and few studies were conducted to explore the anxiety stakeholders' own beliefs, perceptions and attitudes towards the anxiety in terms of asking questions in an enclosed classroom setting.

\subsection{Respondents}

In order to choose the appropriate respondents, formal emails were sent to 50 Chinese MSc TESOL students to ask them about whether or not they experienced FLCSA in asking questions in TESOL classes, and those who had this experience were invited to participate in individual face-to-face interviews. As a result, 3 students reported by email that they had the experience and were willing to take part in this study. In addition, informal daily inquiries were conducted to target the respondents who experienced this type of anxiety. As a result, 4 out of 10 students reported their experience and agreed to participate in this study.

There were 7 respondents in total, among whom there was one male. The respondents were Chinese students who had been enrolled in the MSc TESOL programme at the University of Edinburgh. All respondents were between 22 
and 25 years old. They had been learning English in China for approximately 12 to 15 years. As for their bachelor's degrees, two of them were Chinese majors, and others were English majors. There was only one respondent who had overseas experience of studying and working in US for 6 months. 7 respondents with different backgrounds all had experienced the anxiety induced by asking questions in TESOL classes, which helped to gain a comprehensive understanding of this form of anxiety through different perspectives of diverse respondents.

\subsection{Instruments}

A semi-structured interview schedule was used in order to find out respondents' feelings, thoughts, intentions or beliefs (Creswell, 2012; Denzin \& Lincoln, 2008; Marshall \& Rossman, 2011; Patton, 1990). Respondents were explicitly and implicitly asked a series of flexible questions related to their views on the experience of anxiety in asking questions. Semi-structured interviews enabled the researcher to modify or expand his line of enquiry, and to ask more follow-up questions and uncover underlying reasons in a way that questionnaires cannot (Greener, 2011; Punch, 2009; Robson, 2011; Rubin \& Rubin, 2012; Seidman, 2013). Furthermore, semi-structured interviews enjoy important strengths of establishing close relationships between the interviewer and the interviewee, and of enabling the interviewees to articulate ideas and thoughts without the distortion resulting from a more rigidly structured framework (Gomm, 2004). Apart from interviews, a short questionnaire was employed to collect respondents' background information which was used to help interpret the interview data.

\subsection{Procedures}

There were two stages: pilot interviews and formal interviews. Through pilot interviews, the preliminary interview schedule was gradually refined, and the final version was employed for the formal interviews. From the pilot interviews, a series of open-ended questions were constructed, which enabled the respondents to generate more comprehensive and profound data pertaining to their views on the previous experience. Subsequently, the researcher sent confirming e-mails to the 7 individuals who agreed to take part in the interviews. The interviews were conducted in June 2014. Before each interview, the interviewee was asked to review and sign a consent form required for participation in this study. Furthermore, warm-up questions were asked before each interview so as to make interviewees feel comfortable and willing to share their experiences. Each interview took between 40 minutes to 1 hour, depending on the amount of detail each interviewee was ready to offer. All interviews were tape-recorded in their entirety to ensure the accuracy of data collection. At the end of each interview, the interviewee was thanked and asked to fill in a short questionnaire in order to collect his or her background information. On the completion of each interview, the audiotape was transcribed verbatim.

\subsection{Data Analysis}

The interview data was analysed and interpreted following grounded theory data analysis techniques and procedures. The grounded theory approach is a qualitative research method which adopts a systematic set of procedures to develop an inductively derived grounded theory about a phenomenon (Robson, 2011). The main objective of this approach is to expand upon an explanation of a phenomenon through identifying the essential elements of that phenomenon (FLCSA in asking questions in class), and then categorising the relationships of those elements to the context and process of the research (Patton, 1990). Coding categories were also developed on an ongoing and systematic basis. Additionally, a series of strategies were adopted, including the search for discrepant evidence, inter-rater reliability in the coding process, and peer review at different stages as the study progressed.

\section{Findings and Discussion}

\subsection{Introduction}

This chapter presents the findings and discussion in accordance with the research questions under examination. In order to facilitate tracing references from the data, the following codes are used: $\mathrm{I}=$ interviewer; $\mathrm{R}=$ respondent; $\mathrm{L}$ $=$ line. For example, $(\mathrm{R} 1, \mathrm{~L} 15-20)$ indicates that the reference is from the first interview, Line 15 to Line 20 in the first interview transcript. All interview data references are directly selected from interview transcripts with transcription conventions.

\subsection{RQ1: What do Chinese MSc TESOL students perceive are the effects of their anxiety in asking questions in class?}

The effects of this type of anxiety primarily consist of three components, that is, psychological effect, physical effect, and effect on students' actual speaking performance. In order to obtain a comprehensive understanding of the anxiety in the whole process of asking questions, three stages are identified, that is, before, during and after asking 
questions.

\subsubsection{Psychological Effects}

Before asking questions, respondents predominantly felt nervous and hesitated to ask questions, and they were going through a very complex journey in their mind. In general, they were hesitating whether or not they should ask questions, because they were worried about their speaking proficiency, the value of the questions, and others' negative evaluation. With these worries taking place, respondents felt nervous to ask questions. For example:

before em (..) I think a little hesitated whether to raise my hands or not (.) so I think it is a little bit annoyed to me because I want to ask this question but I have some worries that just stop me from raising my hands (R2, L35-38)

During actually asking questions, respondents' focus was on expressing their questions, and their nervousness began to decrease, but they still felt nervous. For example:

When I'm focusing on asking questions (.) myself I devote myself in thinking in expressing and I feel not that anxious (.) it's kind of process (R7, L39-41)

After finishing asking questions, respondents felt relaxed and relieved under the condition that their speaking was accurate and fluent or they received positive feedback from others. On the contrary, respondents would feel nervous if they were not satisfied with their own speaking performance or they received negative feedback from others. For example:

oh I feel relieved (.) NO! DEPENDS if I expressed what I want to express I feel relieved (.) ... if I got so nervous and I forgot what I'm going to express (.) I feel annoyed and a little upset (R7, L59-66)

Psychological effects of anxiety are a complex construct involved with respondents' cognition and emotions. Cognitively, respondents went through a train of thought and considerations on both their own capabilities and others' responses (Suleimenova, 2013). The anxious individual constantly scanned situations for potential danger signals. In seeking these signals, it is assumed that an individual might not pay adequate attention to the task at hand, which could negatively affect speakers' performance. Emotionally, on the other hand, much cognitive burden engendered a series of unfavourable feelings which echoes the definition of anxiety pertaining to tension, apprehension, nervousness, and worry (Spielberger, 1983). Moreover, these feelings in relation to the English use in the classroom in this study mirror Horwitz et al.'s (1986) distinct definition of FLA which emphasised the complicated feelings, beliefs, perceptions and reactions related to the classroom environment for learning and using a foreign language.

\subsubsection{Physical Effects}

Before asking questions, accelerating heart rate and blushing were reported to be the most common physical reactions. In addition, trembling, hands becoming cold, and feeling hot were also indicated.

During actually asking questions, respondents' physical reactions seemed to be weakening. However, some physical responses were still happening such as accelerating heart rate, blushing and trembling. For example, when asked whether the physical responses continued to happen, R1 said, "yeah continued to happen and it will end until I have asked all" (L363-364). Also, some new physical responses occurred such as muscles tensing, changes of facial expressions, voice changes and out of breath. For example, R3 reported, "maybe my body becomes tenser" (L176), and "my tone of my speaking is quite wired" (L38).

After asking questions, respondents reported that their physical responses disappeared since they felt relaxed. For example, R3 stated, "I feel peaceful and my physical responses disappeared" (L329).

Yet, as indicated above, the actual performance and others' feedback had an impact on the psychological feelings, which in turn affected physical responses. Although respondents did not report evident physical responses after asking questions, it is assumed that they could feel similar responses if they were not satisfied with their speaking performance.

The findings on the physical effects of anxiety discussed above corroborate Yang's (2005) study related to the psychosomatic effects of anxiety. Furthermore, these physical reactions echo some items in FLCAS created by Horwitz et al. (1986), such as 'I tremble when I know that I am going to be called on in language class' and 'I can feel my heart pounding when I am going to be called on in language class'. The close relationship between psychological effect and physical effect reflects the compound consequences of FLCSA (Suleimenova, 2013). 
These findings have confirmed and enriched the understanding of the subtle effects of FLA.

\subsubsection{Effects on Speaking Performance}

Respondents had different views about the effects of anxiety on their actual speaking performance. Most respondents reported that the anxiety exerted a negative impact on their speaking performance, indicating that it made their utterances lack logic, fluency and accuracy. Moreover, it contributed to some tone changes and demotivated respondents to ask questions in effect. For example:

it will make me like (3.0) the sentences I used will be like (..) without any logic (..) it's not logical and structured (R1, L398-399)

However, the anxiety was not without any positive effects. Some respondents claimed that the anxiety made them concentrate on their speaking, which improved the quality of their speech. In addition, the anxiety increased their attention to the questions and teachers' answers, which strengthened their understanding of the knowledge. For example:

I think sometimes it has the negative effects (.) but most of time I think it can increase my attention on this problem on teachers' reactions (.) sometimes it is very positive (R2, L321-323)

Therefore, it could be seen that respondents had different attitudes towards their anxiety. This distinction reflects the dual roles of anxiety, namely, facilitating and debilitating anxiety. As previous studies reported, anxiety could be a conducive facilitator in students' language learning (Al-Shboul et al., 2013). Respondents in previous research also mentioned their favourable attitudes towards the language anxiety in their English learning (e.g., Trang, Baldauf \& Moni, 2013). However, the fact that the majority of respondents (5 out of 7) in this study held a negative attitude towards their anxiety elaborates on the findings claimed by Trang et al. (2013), which echoes the pervasive harmful functions of anxiety indicated by a great deal of studies (e.g., Aida, 1994; Bailey, Onwuegbuzie \& Daley, 2000; Chen \& Lin, 2009; Elkhafaifi, 2005; MacIntyre \& Doucette, 2010; MacIntyre \& Gardner, 1994a; Pappamihiel, 2002; Sellers, 2000; Woodrow, 2006; Yan \& Horwitz, 2008).

The subtle effects of anxiety in asking questions in class happened to students primarily through two ways. Psychologically, students encountered a series of cognition and emotions. This type of anxiety brought about much worry, stress and preoccupation. Under the influence of these psychological effects, physical reactions occurred to anxious students in different ways such as trembling and blushing. Therefore, it could be seen that anxiety in asking questions exerted compound effects upon both students' mind and body.

Apart from these two types of effects, anxiety in asking questions also had a big impact on students' speaking performance. The fluency and accuracy of students' speaking could be negatively affected, as R4 noticed that "my tone of my speaking is quite weird...the fluency and also I feel my speaking is not a normal talking" (L38-42), and R5 reported that "I'm too nervous maybe more questions more details I will forget in my raising questions" (L67-68). Hence, it could be seen that anxiety in asking questions negatively affected students' normal speech and recall. This finding accords with the previous studies related to the effects of anxiety (e.g., MacIntyre \& Gardner, 1989, 1991a, 1994a, 1994b; Suleimenova, 2013). Although anxiety was constantly reported to be an unfavourable element in students' language learning, it cannot be denied that anxiety was also considered as a beneficial component by some students. The facilitating role of anxiety reported by respondents in this study corroborates and develops the previous understanding on the positive function of anxiety in language learning. Nevertheless, in what ways and under what situations anxiety is likely to enhance language learning are still worth further examining.

\subsection{RQ2: What do Chinese MSC TESOL students perceive are the factors that contribute to their anxiety in asking questions in class?}

The second research question regarding the factors contributing to the anxiety under examination is believed to be of crucial importance, as effective strategies for reducing the anxiety are likely to be proposed only if the sources of anxiety are discovered.

\subsubsection{Personal and Interpersonal Anxiety}

Based on the sources suggested by Young (1991), five components related to personal and interpersonal anxiety have been reported by respondents in this study.

\subsubsection{Competitiveness and Comparison}

Although most respondents reported that they did not feel a strong sense of competition in class, their constant 
comparison with peers on such aspects as the speaking proficiency or the content of questions indicated that they were unconsciously competing with others. Competition has two consequences: when respondents thought their performance was worse than others', they were likely to become disappointed and anxious; otherwise, they would feel confident and motivated to ask more questions. For example:

if others are very better than me (.) I will feel very nervous and I'm not dare to open my mouth to speak (.) cus I think I will be like laughed at by others (R1, L139-141)

if I think in this class I know others' proficiency is lower than me I will have the confidence to ask my question and maybe sometimes I want show my speaking proficiency it's possible (R2, L104-107)

It can be seen that competitiveness and comparison are interlocked to each other, and the competitiveness seems to be the key source of anxiety leading to conscious or unconscious comparison. This result reflects Bailey's (1983) claim that the relationship between the learner's competitiveness and self-esteem is a potential source of language anxiety, and competitive nature of L2 learning can result in anxiety when learners compare themselves to others or to the idealised self-images.

\subsubsection{Fear of Negative Evaluation}

Respondents also reported their fear of negative evaluation from their classmates and teachers. They paid much attention to others' comments, feedback or responses. They were fearful of being laughed at, because they felt that their face or self-image was damaged in front of the audience. For example:

em (.) first I have a little worries (.) because I think maybe the teachers will laugh at me and students (.) my classmates will also laugh at me maybe they know the answers but I don't know (R2, L11-13)

yes if I perform poor (.) I will make anyone else in class think about this people not so professional or poor English like that (.) and my face is kind of damaged (.) of course that will influence my asking questions in class (R5, L205-208)

This result indicates that respondents' self-esteem and their fear of negative evaluation are intertwined, as suggested by some studies (e.g., Gregersen \& Horwitz, 2002; Kitano, 2001; Price, 1991; Young, 1991). This finding also mirrors Krashen's argument that the more people think about their self-esteem, the more impressed they are with its impact; students with low self-esteem tend to worry about what their peers think, in fear of negative responses or evaluation. In general, two aspects were reported to result in others' negative evaluation, namely, the speaking proficiency and the content of questions, which will be discussed in the following two factors (Young, 1992).

\subsubsection{Lack of Confidence about English Speaking Proficiency}

Many respondents reported that they were worried about their English speaking proficiency, because lack of fluency or inappropriate expressions could result in teachers' misunderstanding and others' negative evaluation of their English ability. For example:

first I think among the four skills (.) my writing and speaking abilities are poor (.) so first I'm not confident about speaking (.) sometimes my English is not fluent and accurate and this makes teachers misunderstand my questions (.) this kind of thing makes me feel very anxious (R7, L103-107)

As mentioned in the first research question, before asking questions, respondents mostly attempted to organise sentences in their mind so as to speak fluently and accurately, which aimed to make teachers well understand their questions and gain positive feedback from others. Some respondents perceived the language barrier as the fundamental reason for teachers' misunderstanding. For example:

yes (.) but actually the content of my ideas is probably because of the language I used maybe (.) basically (.) the language (R1, L63-64)

This finding demonstrates that learners who perceive their language proficiency to be lower than that of others in class are more likely to feel anxious. Low speaking proficiency might lead to teachers' or classmates' misunderstanding of students' questions, which in turn could result in negative evaluation making students feel losing face. This result has been reported by some studies (e.g., Liu, 2007; Price, 1991; Young, 1991). By contrast, R6 did not feel anxious about her English proficiency, because her overseas experience in the US offered her 
adequate confidence about her English ability:

yes maybe it's my own experience in America I was there for half of a year I was teaching Chinese and sometimes English to primary school students (.) and I was also taking courses I've been tutoring language to foreign students for more than 4 years (.) so I don't feel any nervous about my language (R6, L287-291)

\subsubsection{Lack of Confidence about the Content of Questions}

Apart from the English speaking proficiency, the content of questions was also an important factor contributing to others' negative evaluation and respondents' anxiety. Many respondents mentioned their worries about the value of their questions before asking questions. They had worries that their questions might be considered meaningless, silly, too easy, non-academic or unprofessional by teachers or classmates. For example:

yes (.) I think I will consider whether it is too simple or too shallow (.) so I think the content is also very important for me it is a kind of factor that influences me whether I will ask the question or not (R2, L165-167)

Since asking questions is a way to express thoughts and ideas which can indicate students' understanding of knowledge and intelligence, students attempt to make the content of their questions sophisticated and elaborate in order not to show their ignorance. Much concern about the content of questions brings about hesitation and anxiety in asking questions, since students are fearful of others' negative evaluation, which could subsequently make students feel losing face. This lack of confidence about the content of their questions seems to illustrate the shortage of confidence about the subject matter and the unfamiliarity with the course knowledge. This finding appears to enrich the understanding of sources of FLCSA, since there seems to be limited research mentioning the speaking content contributing to language anxiety.

\subsubsection{Unfamiliarity with Classmates and the Subject Matter}

Some respondents reported that they felt anxious when asking questions in an unfamiliar classroom environment, because they were more likely to be afraid of being laughed at by their unfamiliar classmates. For example:

if I'm familiar with the whole classrooms (.) that will help me to decrease my anxiety (.) because I'm familiar with them and I'm not afraid of losing face like that (R5, L308-310)

in front of more familiar people (.) although you make some mistakes it doesn't matter they are your friends (.) but in lectures the classmates around you are more like strangers (.) so I don't like to ask questions in lecture (.) but in workshops I think fine we are all friends it's okay (R7, L442-446)

In addition, the familiarity with the subject matter also influences respondents' anxiety in asking questions. For example, R3 reported, "for the yy course I will ask a lot of questions cus I know it very well" (L33-35, yy refers to the course name). These findings are consistent with the past research (e.g., MacIntyre, 1998; Young, 1994), which demonstrates that being unfamiliar with classmates could make students feel anxious about speaking in front of others. In addition, lack of knowledge on the subject matter also increases the level of anxiety, since the knowledge lays the foundation for questions. This seems to be a unique feature of the anxiety in asking questions.

\subsubsection{Learner Beliefs about English Language Learning}

Some respondents mentioned their careful attention to the English pronunciation and accent. They were fearful of wrong pronunciations or Chinese accent of English. Due to the fact that they could not acquire an "excellent accent" and sometimes made pronunciation errors, their beliefs about the significance of pronunciation or accent in English speaking proficiency and the realities clashed (Fang-peng \& Dong, 2010). Hence, this contrast between their beliefs and their real performances made them feel unsatisfied with themselves and anxious about asking questions in class. This result is in line with what Ohata (2005) claims, that is, if the learners hold the belief that pronunciation is the single most important aspect of language learning, they will naturally feel frustrated to find the reality of their poor speech pronunciation even after learning and practising for a long time. For example:

I think the most frustrating and embarrassing situation is that (.) a simple word you pronounce it incorrectly. (R7, L193-194)

In addition to the specific errors associated with pronunciation and accent, respondents also stated their unfavourable attitudes towards making errors or mistakes when asking questions. They were worried that errors or mistakes would give others a bad impression of themselves so that their face would be damaged. For example: 
I value too much (.) I care too much (.) I'm afraid of making mistakes because I think mistakes may leave bad impressions to others (R7, L179-181)

when I speaking English asking questions in class (.) if I did some grammatical mistakes and sometimes when you speak out you realised you made a mistake (.) and I became more nervous and it makes me feel losing my face (R4, L200-203)

According to Young (1991), erroneous beliefs about language learning are a great contributing factor to students' language anxiety. The unrealistic perceptions or beliefs on language learning and achievement can result in frustration or anger towards students' own poor performance in a foreign language. These beliefs are most likely to emanate from learners' perfectionist nature (Gregersen \& Horwitz, 2002). For example:

I want to behave perfectly (.) not only to speaking (.) everything including writing because I want to get a higher mark I want to perform perfectly I want to be a good impression on others so when I worry a lot about this (R7, L173-176)

Perfectionist learners attempt to speak flawlessly, with no grammar or pronunciation errors, and as easily as a native speaker - these high or ideal standards create an ideal situation for the arousal of language anxiety (Gregersen \& Horwitz, 2002).

\subsubsection{Role of Instructors}

In accord with previous studies, this study also found that students' anxiety may be aggravated by the role played by teachers in class (Onwuegbuzie, Bailey \& Daley, 1999).

\subsubsection{Teachers' Personality}

Many respondents claimed that their teachers' personality had a strong relationship with their anxiety. If the teachers were very strict or unfriendly, respondents would feel hesitated or nervous to ask questions not only in class but also after class. Respondents preferred to ask questions to those teachers who were nice and considerate. For example:

if the teacher is more nice ((laughs)) very easy-going (.) I feel more at ease to ask questions (.) I will not be afraid of making mistakes (.) but I evaluate that teacher is very strict or very unfamiliar with (.) I will like (..) my anxiety will go up (R1, L433-436)

\subsubsection{Teachers' Attitudes towards Questions}

The teachers' attitudes towards students' questions have been reported to be significantly related to FLCSA. Some respondents reported that they felt anxious when teachers showed indifferent attitudes towards their questions. For example:

sometimes the teacher just wants to finish this lesson as quick as they can (.) and they didn't show they really want to hear questions (R6, L239-241)

Some respondents also mentioned that teachers refused to answer their questions, since teachers thought the questions could be answered by students themselves. For example:

maybe in yy's class maybe she just said that you could find that on book (.) I will not waste this time for you to answer this question (.) we will go on something like that this makes me very frustrated (R3, L250-252, yy refers to a teacher)

I feel they are not willing to answer your questions directly (.) because they think the question is very shallow you can just find out by yourself (R5, L169-171)

\subsubsection{Teachers' Feedback to Questions}

In addition, respondents stated that the way teachers gave feedback to their questions could trigger their anxiety. R4 reported her painful experience of being embarrassed in front of the whole class primarily because of the teacher's one-sentence response "what did you mean":

I felt very EMBARRASSED (.) cus I really tried my best and told myself several times you can do it (.) when I finished that question she just said "what did you mean" (.) I felt really disappointed and this may affect my following workshops and I don't ask questions any more (R4, L281-285)

This traumatic experience of asking questions in class greatly curtailed the student's motivation to ask questions and increased her speaking anxiety. However, it can be possible that the teacher did not at all aim to embarrass R4 
at that time; rather, the teacher might not be aware of the significant impact of her response to students' questions. Similar painful experiences were also reported in Price's (1991) study.

\subsubsection{Students' Personality}

Respondents held different views about the relationship between their own personality and their anxiety in asking questions. Some respondents considered themselves introverted, and they believed that this type of personality generated anxiety for them to ask questions in class. For example:

yes! yes! it has a strong relationship between my characteristic and my anxiety (.) cus I'm a very shy people (.) I'm reluctant to show my feeling or perform in the classroom (.) I speak less in the classroom and just sit silently to wait for others to ask the questions rather than by myself (R5, L298-302)

A different respondent considered her ambitious personality as a contributing factor to her anxiety in asking questions in class:

I think another thing goes with my personality I'm kind of an ambitious person (.) I always want to win (.) I have a very high self-esteem (R7, L163-165)

Although R7 considered her ambition as part of her personality, it is better to indicate that her ambition reflects the perfectionist belief about language learning which encourages individuals to make no errors or mistakes in their speaking performance (Gregersen \& Horwitz, 2002). This self-perceived personality echoes R7's unrealistic belief about language learning.

\subsubsection{Students' Educational and Cultural Background}

Most respondents considered the previous education in China as an underlying reason for their anxiety. They suggested that they were predominantly taught to memorise knowledge from teachers, rather than actively ask teachers questions. They had been used to being passively fed by teachers, and it was difficult for them to change their learning styles and establish a new learning style, even though the British educational environment was encouraging them to ask questions. For example:

I think it's hard for me to change (.) cus you know the kind of thinking pattern doesn't be built in a few days (.) I have adapted to the Chinese thinking pattern for 20 years (R5, L322-324)

In addition, some respondents reported that Confucius philosophy in China was related to their anxiety in asking questions in class. For example:

in China the mainland China (.) the Confucius philosophy really influenced the way we learned before (.) so we were told that silence is gold (.) and you should answer the question then raise your hand and the teacher asks you to answer that (.) so I think it's to show respect to other people (.) and I don't want to take time of other students (.) maybe they also want to ask other questions which is more valuable than mine (R6, L78-84)

Furthermore, it was believed by some respondents that the status of teachers was higher than that of students, and thus they did not feel free to ask teachers questions since they were afraid of challenging teachers' authority and prestige. For example:

in China we respect the teacher which makes me feel the teacher is higher than students (.) when I ask question to the teachers (.) then I will feel I'm challenging the authority something like that and that will make me feel nervous (R5, L314-318)

The cultural difference between foreign students and native speakers of the target language is a major anxiety-triggering factor. Different understandings on asking questions and student-teacher relations between Chinese culture and western culture appear to prevent Chinese students from asking questions in class. This finding mirrors Jones's (2004) claim that language anxiety is a concern of face in different cultures. It seems that those students who consider asking questions as showing off or challenging the teachers' status aim to save both their own face and teachers' face. The belief of unequal status between students and teachers is also consistent with the previous research regarding the impact of social status on speakers' language and behaviour (Carrier, 1999; Pica, 1987).

\subsubsection{Time for Asking Questions}

The majority of respondents agreed that interrupting teachers to ask questions in class was much more 
anxiety-provoking than asking questions when teachers gave the floor to the whole class. For example:

yes I feel very anxious when I need to interrupt the teacher (.) because you know people were listening to her and she has her own lesson plan (.) you just took other people's time so you need to think more like do I really need to ask this? is it okay? so I was more anxious (R6, L359-363)

This contributing factor could be explained through the perspective of face concern. Provided that a student interrupts the teacher whilst he or she is teaching in class, the student would draw almost all attention from others. Thus, it is more likely for the student to encounter others' negative evaluation which leads to losing his or her face. This finding seems to indicate the special feature of asking questions in class.

\subsection{RQ3: What strategies do Chinese MSc TESOL students adopt to effectively cope with their anxiety in asking questions in class?}

Respondents adopted a variety of strategies to cope with their anxiety. The strategies will be illustrated in accordance with the three stages of asking questions, namely, before, during and after.

\subsubsection{Before Asking Questions}

Respondents reported four main strategies that they used to cope with their anxiety in asking questions in class.

\subsubsection{Preparation}

"Preparation" was the most frequently mentioned word when respondents were asked about the effective strategies they used to cope with their anxiety before asking questions. One of the most common ways of preparation was to prepare questions before classes through reading reference materials or discussing with group members. By means of preparation, respondents were likely to express their questions more fluently and accurately so as to reduce the fear of their speaking performance and the content of their questions. For example:

I will prepare question which might be asked in the next workshop (.) and then I study at home and to prepare the questions first and I would like to (.) speak the questions once before I go to the workshop (.) and that makes like I'm expressing very fluently or more accurately (R1, L75-79)

This effective coping strategy confirms previous studies (e.g., Kondo \& Ying-Ling, 2004; Ohata, 2005).

Interestingly, R1 pointed out the disadvantage of preparing questions before class:

I mean cus I have said I will prepare myself to ask questions (.) before workshops cus I know what's going to happen in the workshop (.) but sometimes the teacher will like oh you have I think you have already known these questions then just pass these and talk about other issues (..) and then: these are not my prepared questions (R1, L546-551)

yeah out of my prediction ((laughs)) I think the preparation will sometimes restrict your: how to say (3.5) xianzhi nide siwei (restrict your thinking and ideas) (R1, L553-555)

This appears to be a new finding regarding the strategy of preparation for coping with language anxiety. Therefore, how to prepare questions before class is worth exploring.

\subsubsection{Self-encouragement}

In line with past research (e.g., Kondo \& Ying-Ling, 2004; Ohata, 2005; Young, 1992), self-encouragement was perceived as another important and useful strategy to cope with language anxiety. For example:

it's like self-encouragement and tell myself don't be nervous ((laughs)) it's just a little thing (.) it doesn't matter (R7, L73-74)

Some respondents even regarded asking questions as a mission and challenged themselves to complete it. For example:

challenge myself to be brave in front of the public and to challenge the things that I haven't tried before (.) so I think it's a challenge for me to help myself be brave to be more brave than before (R2, L361-364)

In addition, some respondents warned themselves not to lose opportunities for asking questions, since they could need much more time to find the answers to questions. For example:

I just told myself (.) if I don't ask the question at this point maybe I need to use ten times 
time after class (R3, L427-428)

Based on respondents' accounts, it can be seen that self-encouragement can be practised in several ways such as self-challenge and self-warning. The strategy of self-encouragement echoes some studies (e.g., Hu, 2011; Kondo \& Ying-Ling, 2004; Onwuegbuzie et al., 1999). Further, different ways of self-encouragement discovered in this study have enriched the understanding of how self-encouragement helps reduce students' language anxiety.

\subsubsection{Peer Seeking}

In order to make sure questions were professional or not silly, respondents asked peers for their opinions on the questions. If peers gave positive feedback on the questions, respondents would obtain much encouragement and motivation to ask questions. This method helped respondents to check both the expression and the content of questions. For example:

I may ask my peers (.) before (.) to make sure my questions are not so shallow or silly (R5, L110-112)

Apart from this, respondents also told themselves that others also felt anxious about asking questions, or others' English or questions might be worse than theirs. In this way would respondents gain confidence about their speaking proficiency and the value of their questions. For example:

maybe I will tell myself that you are not the poorest person in class ((laughs)) and everyone else may be worse than you or we're just in the same level (.) I just persuade myself (R5, L212-214)

This finding confirms Oxford's (1999) claim that peers can provide much help to reduce students' speaking anxiety in class.

\subsubsection{Relaxation}

Some strategies for relaxation were employed by respondents to ease their anxiety. Taking a deep breath, trying to calm down and drinking a cup of coffee were pointed out. For example:

like to give a deep breath I think it's really helpful for me to have a clear mind (.) and then I will know what to say next and that will become a good circle (R4, L379-381)

R5 suggested that he thought about something pleasant when he felt nervous in class such as a delicious meal, favourite films or music:

maybe how about my lunch my dinner (.) or how about some kind of movie or music to help me relax (R5, L355-356)

These methods for managing language anxiety have been constantly reported by the past research (e.g., Kondo \& Ying-Ling, 2004; Melouah, 2013; Ohata, 2005).

\subsubsection{During Asking Questions}

When respondents were actually asking questions in class, they might also adopt the strategies mentioned above to cope with their anxiety. For example, they could be still encouraging themselves to express their questions with confidence. When they encountered some difficulties during their speaking, they could also turn to their peers for help. However, one new strategy which some respondents pointed out was to slow down their speaking speed in order to avoid pronunciation errors and make their questions clear. For example:

I will try to slow down my speed of my speaking (.) and try to make my speaking English clear and you will feel less nervous than before (R4, L374-375)

I mentioned I'm afraid of pronunciation mistakes (.) so I may try to slow down the speed try to pronounce clearly word by word try to make the teachers understand (.) I think this is another way to reduce my anxiety (R7, L463-466)

In addition, R4 reported that body language such as gestures, was useful to reduce her anxiety:

if I use body languages like some gestures (.) that will help me to calm down and try to relax my feeling (R4, L46-48)

Strategies of slowing down speaking speed and using body language seem to be rarely reported by previous studies. Although some respondents in this study considered these two strategies effective to reduce their anxiety in asking questions, more research is needed to check this argument and further investigate how these two strategies help 
alleviate language anxiety.

\subsubsection{After Asking Questions}

After asking questions, two main strategies were reported by respondents to cope with their anxiety in asking questions in class.

\subsubsection{Ignoring Others' Evaluation}

After asking questions, R5 reported that he tried to focus on teachers' answers and ignore others' negative feedback if any. He also gave himself compliments for completing the task of asking questions:

I: so did you do something to reduce your anxiety after you ask questions

$\mathrm{R}$ : just ignore the questions after I ask and just ignore yeah

I: how did you ignore (.) what did you think about

R: let it be ((laughs)) just don't concern about the questions and don't worry about others'

evaluation (.) I also praise myself for finishing asking questions (R5, L53-59)

This countermeasure for reducing anxiety is a form of self-encouragement which can provide students with positive cognition to help them keep away from others' influence (Price, 1991). However, it might be difficult for students to completely get rid of others' evaluation, since they care about their face often unconsciously and tend to please others with their questions.

\subsubsection{Practice after Class}

If respondents were not satisfied with their speaking performances, they would take measures to improve themselves. In order to enhance their spoken English, they made friends with non-Chinese international students to practise speaking English. Also, they listened to English radio and watched English programmes. They tried to seek many chances to practise their English. For example:

I think first of all try to speak more (.) maybe encourage myself to speak English (R7, L295-296)

On the other hand, if they found themselves lack of the subject knowledge which contributed to their anxiety, they would study harder to make themselves more familiar with the subject matter so as to increase their confidence about the content of questions in the following classes. For example:

I: okay did you do something to enlarge your knowledge in order to reduce your anxiety

R: don't cry go to the library to read more ((laughs)) (R5, L344-346)

This reported coping strategy echoes some previous studies (e.g., Hu, 2001; Kondo \& Ying-Ling, 2004; Ohata, 2005; Oxford, 1999), which suggest that practice is an essential method to reduce students' language anxiety, because only through persistent practice could students enhance their speaking ability and courage to express themselves in public.

Despite the variety of strategies discussed here, as well as those reported in previous studies, language anxiety appears to continue to flourish in the classroom. These strategies seem to be a guideline for teachers and learners, rather than a treatment of language anxiety. This also corroborates the view that language anxiety is a complex psychological phenomenon, one which demands special attention from the instructors and learners if it is to be sufficiently managed (Horwitz, 1986; MacIntyre, 1998). Nevertheless, it can be postulated that, to a considerable extent, apt application of these strategies can reduce anxiety in asking questions, even though they cannot completely alleviate it.

\section{Conclusion}

Anxiety in asking questions in class exerts compound effects on students' mind and body as well as their speaking performance. These three effects of anxiety, namely psychological, physical and behavioural ones, are interrelated to one another. This study has enriched the understanding of the manifestations and consequences of FLA and FLCSA.

Under the guidance of the six potential sources of language anxiety suggested by Young (1991), a variety of reasons for students' anxiety in asking questions have been discovered. In general, two main elements are involved with this anxiety, namely, students and teachers. This study has corroborated the findings about the sources of FLA reported 
by previous research. More importantly, some new factors contributing to FLCSA in terms of asking questions in class have been recovered, which helps enrich the theory of the construct of FLA and FLCSA.

Preparation, self-encouragement, peer seeking, relaxation, practice, and ignoring others' negative evaluations constitute the repertoire of strategies reported by respondents. This study has provided a series of effective strategies for ESL/EFL learners to reduce their anxiety in asking questions in class, which would in turn improve their language development and benefit their comprehension of the subject matter. Further, this study has enriched the understanding of how students can effectively cope with their FLA and FLCSA.

\section{Recommendations}

\subsection{Recommendations for ESL/EFL Instructors}

1) First and foremost, ESL/EFL instructors should acknowledge the existence of the feeling of anxiety in asking questions in class. They should take initiatives for its effective reduction. Based on the reported effects of anxiety on learners, instructors ought to identify individuals with signs of stress and anxiety and apply appropriate strategies to help them counteract these feelings.

2) For active participation in the classroom discussion, it should be ensured that students are provided with friendly and learning-supportive environments. This can be achieved by teachers' friendly, helpful and cooperative behaviors, which can make students feel comfortable when asking questions or speaking English in class. This is also conducive to reducing, although not eliminating altogether, the social and status difference between students and teachers in order to establish a close relationship between them.

3) Teachers should attach much attention to their responses to students' questions, since their negative feedback would trigger or aggravate students' anxiety. Teachers should provide students with detailed answers to their questions with an attitude of patience and enthusiasm. In addition, a period of time in class particularly for answering students' questions should be provided by teachers.

4) As students are fearful of making errors or mistakes, teachers should encourage students to have the confidence to make them in order to improve their speaking skills and modify their subject knowledge. Moreover, teachers should show students their welcoming attitudes towards questions, and encourage students to actively ask questions in class.

5) It is also recommended that teachers should confront students' erroneous and irrational beliefs through cultivating in them "reasonable commitments for successful language learning" (Onwuegbuzie et al., 1999, p. 232). These beliefs can be modified by instilling realistic expectations and reasonable performance standards in the learners and by raising their awareness of the slow progress of mastering a foreign language. For example, teachers can tell students to be tolerant towards their own accent of English, and encourage them to ask questions without much concern about their non-native English pronunciation. On the other hand, teachers can provide some guidance to help students polish their pronunciation or accent.

6) Familiarity with classmates can also assist students in reducing their anxiety in class. Hence, teachers should carry out some interactive activities to create a sense of friendship and cooperation among students. This would help to reduce the sense of competition among students. Therefore, this would help students to ask questions more confidently and with less anxiety in the class.

7) Finally, there should be some specific teacher training programmes on language anxiety in order to make teachers aware of this complex issue, and provide them with effective countermeasures to reduce students' anxiety in asking questions in class.

\subsection{Recommendations for ESL/EFL Learners}

1) Since questions are based on sufficient understanding of the subject matter, it is suggested that students should carefully preview the course content through critical reading and active discussion with peers, in order to prepare meaningful questions, rather than silly or shallow ones. Adequate preparation for questions has been reported to be a very effective strategy to reduce the anxiety induced by asking questions in class.

2) Practising speaking English is also strongly recommended for students. Since lack of confidence about English speaking proficiency is considered as a primary reason for the anxiety, practice seems to be the most important and practical method to improve English speaking skills, which in turn enhances students' confidence about their spoken English and motivates them to ask questions in class. 
3) It is also suggested that students should cultivate positive attitudes towards their anxiety in asking questions. When facing this anxiety, students should encourage themselves with positive thinking in order to bravely ask questions in class. Self-encouragement can provide students with much energy to take the action of asking questions in class. Also, students could do some relaxation to ease themselves.

4) Students should be aware of the differences between Chinese and western educational cultures. Since western education seems to emphasise more the interaction and equal status between teachers and students, it appears unnecessary for students studying in an ESL classroom to worry about the negative evaluation of actively asking questions.

\subsection{Recommendations for Future Research}

1) So far there has been limited research into English language anxiety in an ESL context; therefore, it is not clear whether the anxiety in asking questions in class is typical of Chinese MSc TESOL students studying in the UK. More research on language anxiety with students of different majors and different nationalities would be useful in clarifying this question. In addition, other research sites should be employed to look into this issue more comprehensively.

2) Although a series of practical recommendations on how to reduce students' anxiety in asking questions in class have been proposed, there is a need for empirical evidence concerning how effective these anxiety-reducing techniques are in foreign language learning classrooms.

3) Asking questions in class is just one of the speaking activities, and thus future research is expected to examine other speaking activities such as answering questions, doing presentations and so on. FLCSA induced by different speaking activities should be understood in a more profound and comprehensive way, which in turn would benefit a better understanding of the FLA construct.

4) Considering the crucial role of teachers in foreign language pedagogy, future researchers on language anxiety should attempt to explore teachers' beliefs and perceptions about language learning and teaching, and language anxiety, in addition to those of learners, as a means to effectively address the multi-dimensional construct of language anxiety.

\section{Acknowledgements}

I am deeply indebted to my supervisor, Dr Charlotte Kemp, who provided me with stimulating suggestions and enduring encouragement throughout the time I was researching and writing my master dissertation, which serves as the foundation for this article.

I would like to extend my special thanks to the co-author, Randhir Roopchund, who offered me many insightful and valuable suggestions to complete this article.

Finally, I am extremely thankful to all the respondents who provided me with rich and detailed data for this study, and lent breadth and value to the research findings.

\section{References}

Aida, Y. (1994). Examination of Horwitz, Horwitz, and Cope's construct of foreign language anxiety: The case of students of Japanese. The Modern Language Journal, 78(2), 155-168. http://dx.doi.org/10.1111/j.1540-4781.1994.tb02026.x

Al-Shboul, M. M., Ahmad, I. S., Nordin, M. S., \& Rahman, Z. A. (2013). Foreign language anxiety and achievement: Systematic review. International Journal of English Linguistics, 3(2), 32-45. http://dx.doi.org/10.5539/ijel.v3n2p32

Bailey, K. M. (1983). Competitiveness and anxiety in adult second language learning. In H. W. Seliger, \& M. H. Long (Eds.), Classroom oriented research in second language acquisition (pp. 67-102). New York: Newbury House Publishers.

Bailey, P., Onwuegbuzie, A. J., \& Daley, C. E. (2000). Correlates of anxiety at three stages of the foreign language learning process. Journal of Language and Social Psychology, 19(4), 474-490. http://dx.doi.org/10.1177/0261927X00019004005

Barbour, R. (2008). Introducing qualitative research: A student guide to the craft of doing qualitative research. 
London: Sage.

Bogdan, R. C., \& Biklen, S. K. (2007). Qualitative research for education: An introduction for theories and methods. London: Pearson Education.

Booth, W. C., Colomb, G. G., \& Williams, J. M. (2008). The craft of research. Chicago: University of Chicago Press.

Carrier, K. (1999). The Social environment of second language listening: Does status play a role in comprehension. The Modern Language Learning, 83(1), 65-79. http://dx.doi.org/10.1111/0026-7902.00006

Chen, M. C., \& Lin, H. J. (2009). Self-efficacy, foreign language anxiety as predictors of academic performance among professional program students in a general English proficiency writing test. Perceptual and Motor Skills, 109(2), 420-430. http://dx.doi.org/10.2466/pms.109.2.420-430

Cohen, L., Manion, L., \& Morrison, K. (2000). Research methods in education. London: Routledge Falmer.

Creswell, J. W. (2012). Qualitative inquiry and research design: Choosing among five approaches. London: Sage.

Denzin, N. K., \& Lincoln, Y. S. (2008). The landscape of qualitative research. London: Sage.

Dillon, J. T. (1988). The remedial status of student questioning. Journal of Curriculum, 20(3), 197-210. http://dx.doi.org/10.1080/0022027880200301

Elkhafaifi, H. (2005). Listening comprehension and anxiety in the Arabic language classroom. The Modern Language Journal, 89(2), 206-220. http://dx.doi.org/10.1111/j.1540-4781.2005.00275.x

Fang-peng, G., \& Dong, Y. (2010). A study on college students' anxiety to spoken English. Canadian Social Science, $6(2), 95-101$.

Gomm, R. (2004). Social research methodology: A critical introduction. New York: Palgrave Macmillan.

Greener, I. (2011). Designing social research: A guide for the bewildered. London: Sage.

Gregersen, T., \& Horwitz, E. K. (2002). Language learning and perfectionism: Anxious and non-anxious language learners' reactions to their own oral performance. The Modern Language Journal, 86(4), 562-570. http://dx.doi.org/10.1111/1540-4781.00161

Hickerson, N. (1992). Emics and etics: The insider/outsider debate. American Anthropologist, 94(1), 186-187. http://dx.doi.org/10.1525/aa.1992.94.1.02a00250

Horwitz, E. K. (2001). Language anxiety and achievement. Annual Review of Applied Linguistics, 21, 112-126. http://dx.doi.org/10.1017/S0267190501000071

Horwitz, E. K., \& Young, D. J. (1991). Language anxiety: From theory and research to classroom implications. Englewood cliffs, NJ: Prentice Hall.

Horwitz, M. B., Horwitz, E. K., \& Cope, J. (1986). Foreign language classroom anxiety. In E. K. Horwitz, \& D. J. Young (Eds.), Language anxiety: From theory and research to classroom implications (pp. 27-39). Englewood Cliffs, NJ: Prentice Hall.

$\mathrm{Hu}, \mathrm{W}, \mathrm{C}$. (2011). Non-English majors' English learning anxiety and their use of self-regulatory strategies. Unpublished master's thesis, Huazhong University of Science and Technology. Retrieved May10, 2014, from China Masters' Theses Full-text Database.

Huang, J. (1998). Students' learning difficulties in a second language speaking classroom. Paper presented at the Annual Meeting of the American Educational Research Association, San Diego, 13-17, April.

Jones, J. F. (2004). A cultural context for language anxiety. EA (English Australia) Journal, 21(2), 30-39.

Kim, S. (2006). Academic oral communication needs of East Asian international graduate students in non-science and non-engineering fields. English for Specific Purposes, 25(4), 479-489. http://dx.doi.org/10.1016/j.esp.2005.10.001

Kitano, K. (2001). Anxiety in the college Japanese language classroom. The Modern Language Journal, 85(4), 549-566. http://dx.doi.org/10.1111/0026-7902.00125

Koch, A. S., \& Terrell, T. D. (1991). Affective reactions of foreign language students to natural approach activities and teaching techniques. In E. K. Horwitz, \& D. J. Young (Eds.), Language anxiety: From theory and research to classroom implications (pp. 109-126). Englewood cliffs, NJ: Prentice Hall. 
Kondo, D. S., \& Ying-Ling, Y. (2004). Strategies for coping with language anxiety: The case of students of English in Japan. ELT Journal, 58(3), 258-265. http://dx.doi.org/10.1093/elt/58.3.258

Liu, M. (2007). Anxiety in oral English classrooms: A case study in China. Indonesian Journal of English Language Teaching, 3(1), 119-137.

Liu, M., \& Jackson, J. (2008). An exploration of Chinese EFL learners' unwillingness to communicate and foreign language anxiety. The Modern Language Journal 92(1), 71-86. http://dx.doi.org/10.1111/j.1540-4781.2008.00687.x

MacIntyre, P. D. (1998). Language anxiety: A review of the research for language teachers. In D. J. Young (Ed.), Affect in foreign language and second language learning: A practical guide to creating a low-anxiety classroom atmosphere (pp. 24-45). Boston: McGraw-Hill.

MacIntyre, P. D. (2007). Willingness to communicate in the second language: Understanding the decision to speak as a volitional process. The Modern Language Journal 91(4), 564-576. http://dx.doi.org/10.1111/j.1540-4781.2007.00623.x

MacIntyre, P. D., \& Doucette, J. (2010). Willingness to communicate and action control. System, 38(2), 161-171. http://dx.doi.org/10.1016/j.system.2009.12.013

MacIntyre, P. D., \& Gardner, R. C. (1989). Anxiety and second language learning: Toward a theoretical clarification. Language Learning, 39(2), 251-275. http://dx.doi.org/10.1111/j.1467-1770.1989.tb00423.x

MacIntyre, P. D., \& Gardner, R. C. (1991a). Language anxiety: Its relation to other anxieties and to processing in native and second languages. Language Learning, 41(4), 513-534. http://dx.doi.org/10.1111/j.1467-1770.1991.tb00691.x

MacIntyre, P. D., \& Gardner, R. C. (1991b). Methods and results in the study of anxiety and language learning: A review of the literature. Language Learning, 41(1), 85-116. http://dx.doi.org/10.1111/j.1467-1770.1991.tb00677.x

MacIntyre, P. D., \& Gardner, R. C. (1994a). The effects of induced anxiety on three stages of cognitive processing in computerized vocabulary learning. Studies in Second Language Acquisition, 16(1), 1-17. http://dx.doi.org/10.1017/S0272263100012560

MacIntyre, P. D., \& Gardner, R. C. (1994b). The subtle effects of language anxiety on cognitive processing in the second language. Language Learning, 44(2), 283-305. http://dx.doi.org/10.1111/j.1467-1770.1994.tb01103.x

Mak, B. S., \& White, C. (1997). Communication apprehension of Chinese ESL students. Hong Kong Journal of Applied Linguistics 2(1), 81-96.

Marshall, C., \& Rossman, G. B. (2011). Designing qualitative research. London: Sage.

Matsuda, S., \& Gobel, P. (2004). Anxiety and predictors of performance in the foreign language classroom. System 32(1), 21-36. http://dx.doi.org/10.1016/j.system.2003.08.002

Melouah, A. (2013). Foreign language anxiety in EFL speaking classrooms: A case study of first-year LMD students of English at Saad Dahlab University of Blida, Algeria. Arab World English Journal, 4(1), 64-76.

Merriam, S. B. (2009). Qualitative research: A guide to design and implementation. London: Jossey-Bass.

Ohata, K. (2005). Language anxiety from the teacher's perspective: Interviews with seven experienced ESL/EFL teachers. Journal of Language and Learning, 3(1), 133-155.

Onwuegbuzie, A, J., Bailey, P., \& Daley, C, E. (1999). Factors associated with foreign language anxiety. Applied Psycholinguistics, 20(2), 217-239. http://dx.doi.org/10.1017/S0142716499002039

Onwuegbuzie, A. J., Bailey, P., \& Daley, C. E. (2000). Cognitive, affective, and personality, and demographic predictors of foreign-language achievement. The Journal of Educational Research, 94(1), 3-15. http://dx.doi.org/10.1080/00220670009598738

Oxford, R. L. (1999). Anxiety and the language learner: New insights. In J. Arnold (Ed.), Affect in language learning (pp. 58-67). Cambridge: Cambridge University Press.

Pappamihiel, N. E. (2002). English as a second language students and English language anxiety: Issues in the mainstream classroom. Research in the Teaching of English, 36(3), 327-355.

Patton, M. Q. (1990). Qualitative research and evaluation methods. London: Sage. 
Pica, T. (1987). Second language acquisition, social interaction, and the classroom. Applied Linguistics, 8(1), 3-21. http://dx.doi.org/10.1093/applin/8.1.3

Price, M. L. (1991). The subjective experience of foreign language learning anxiety: Interviews with anxious students. In E. K. Horwitz \& D. J. Young (Eds.), Language anxiety: From theory and research to classroom implications (pp. 166-172). Englewood Cliffs, NJ: Prentice Hall.

Punch, K. F. (2009). Introduction of research methods in education. London: Sage

Robson, C. (2011). Real world research. Chichester: Wiley.

Rubin, H. J., \& Rubin, I. S. (2012). Qualitative interviewing: The art of hearing data. London: Sage.

Seidman, I. (2013). Interviewing as qualitative research: A guide for researchers in education and the social sciences. New York: Teachers College Press.

Sellers, V. D. (2000). Anxiety and reading comprehension in Spanish as a foreign language. Foreign Language Annuals, 33(5), 512-520. http://dx.doi.org/10.1111/j.1944-9720.2000.tb01995.x

Spielberger, C. D. (1983). Manual for the state-trait anxiety inventory. Palo Alto, CA: Consulting Psychologists Press.

Suleimenova, Z. (2013). Speaking anxiety in a foreign language classroom in Kazakhstan. Procedia-Social and Behavioural Sciences, 93, 1860-1868.

Trang, T., Baldauf, R., \& Moni, K. (2013). Foreign language anxiety: Understanding its status and insiders' awareness and attitudes. TESOL Quarterly, 47(2), 216-246. http://dx.doi.org/10.1002/tesq.85

Woodrow, L. (2006). Anxiety and speaking English as a second language. RELC Journal, 37(3), 308-328. http://dx.doi.org/10.1177/0033688206071315

Yan, X., \& Horwitz, E. K. (2008). Learners' perceptions of how anxiety interacts with personal and instructional factors to influence their achievement in English: A qualitative analysis of EFL learners in China. Language Learning, 58(1), 151-183. http://dx.doi.org/10.1111/j.1467-9922.2007.00437.x

Yang, T. (2005). Measurement of Korean EFL college students' foreign language classroom speaking anxiety: Evidence of psychometric properties and accuracy of a computerised adaptive (CAT) with dichotomously scored items using a CAT simulation. Unpublished doctor's thesis. The University of Texas at Austin. (Publication No. AAT3204228)

Young, D. J. (1990). An investigation of students' perspectives on anxiety and speaking. Foreign Language Annals, 23(6), 539-553. http://dx.doi.org/10.1111/j.1944-9720.1990.tb00424.x

Young, D. J. (1991). Creating a low-anxiety classroom environment: What does language anxiety research suggest. The Modern Language Journal, 75(4), 426-439. http://dx.doi.org/10.1111/j.1540-4781.1991.tb05378.x

Young, D. J. (1992). Language anxiety from the foreign language specialist's perspective: Interviews with Krashen, Omaggio Hadley, Terrell, and Rardin. Foreign Language Annals, 25(2), 157-172. http://dx.doi.org/10.1111/j.1944-9720.1992.tb00524.x

Young, D. J. (1994). New directions in language anxiety research. In C. A. Klee (Ed.), Faces in a crowd: The individual learner in multisection courses (pp. 3-46). Boston: Heinle \& Heinle. 